\title{
Study on Dry Deposition Velocity of Particulate Nuclide onto Sea Surface
}

\author{
Kehan Ouyang ${ }^{1,}$ a , Wenzhen Chen ${ }^{1, b}$ \\ ${ }^{1}$ Naval University of Engineering, Wuhan, China \\ aoykh1990@126.com, bcwz2@21cn.com
}

Keywords: dry deposition velocity, particulate nuclide, sea surface

Abstract. This Particulate nuclide deposit onto the sea surface will bring radioactive hazards to marine ecological environment, so it is necessary to study the dry deposition velocity of it onto sea surface. In this paper, a model of dry deposition of particulate nuclide onto sea surface is established, and the reliability of the model is verified by experimental data. Then, effects of the diameter, wind speed, and particle density on dry deposition velocity is analyzed. It is found that (1) For small nuclides, the deposition velocity is inversely proportional to diameter; for large nuclide, that is proportional to the diameter. (2) For very small diameter nuclides, the larger wind speed is, the higher dry deposition velocity is. for larger particles, that is insensitive to wind speed; (3) The influence of nuclide particle density on dry deposition velocity is related to the diameter. The dry deposition velocity of nuclide particle with a small diameter is insensitive to the density, and that of large diameter particle is proportional to the density. The results of this paper will help to accurately predict the spatial and temporal distribution of nuclide in ocean atmospheric and the amount of nuclide deposited on the sea surface.

\section{Introduction}

After a severe nuclear reactor accident, a large amount of radionuclides will be released into the atmosphere, disperse to other areas, and deposit on the ground due to dry and wet deposition processes [1]. Dry deposition must be considered when simulating atmospheric diffusion and deposition on the surface [2]. Recently, there are many researchers have investigated the dry deposition of particulate nuclides. Vargas analyzed the deposition velocity of ${ }^{137} \mathrm{Cs}$ and ${ }^{134} \mathrm{Cs}$ in Spain after the Fukushima Dai-Ichi Nuclear Power Plant accident [3]. Wershofen measured the dry deposition velocity of iodine-129 onto grass discharged by a nuclear fuel reprocessing plant [4]. Mohan systematically analyzed the overall scenario of dry deposition research, and concluded that an in-depth knowledge on transport and subsequent mass transfer are needed to accurately calculate the dry deposition velocity [5].For a floating nuclear power platform on the sea, the released nuclides will disperse in the marine atmosphere after a serious accident. Therefore, in order to accurately predict the spatial and temporal distribution of airborne nuclides after an accident, it is necessary to establish a dry deposition velocity calculation model for the sea surface.

In this paper, we established the calculation model of dry deposition velocity of nuclide particle onto sea surface, analyzed the effects of the diameter, wind speed, and particle density on dry deposition.

\section{Calculation model}

At present, a large number of studies mainly reflect the dry deposition process by defining the dry deposition rate, and this parameter is also used to correct the atmospheric diffusion and dry deposition of airborne nuclide. The dry deposition velocity of pollution is defined as the ratio of its vertical flux to its concentration at the reference height, as follows:

$$
v_{d}(z)=-\frac{F}{C(z)} .
$$


Where $v_{d}$ is dry deposition velocity $(\mathrm{m} / \mathrm{s}), F$ is vertical flux of pollution $\left(\mathrm{kg} /\left(\mathrm{m}^{2} \bullet \mathrm{s}\right)\right), C(z)$ is concentration of that at height $\mathrm{z}$ in the atmosphere $\left(\mathrm{kg} /\left(\mathrm{m}^{3}\right)\right.$.

Model formula. In this paper, we used the dry deposition resistance model proposed by Slinn to calculate the dry deposition velocity onto sea surface [6]. This model is still used as a reference model for the deposition of particulate matter on the water surface. As shown in Fig. 1, the atmosphere at the reference height (usually $10 \mathrm{~m}$ ) on the surface of the sea is divided into two layers in the vertical direction, that is, the underlying sedimentary layer and the above constant flux layer, in which the thickness of the sedimentation layer is extremely thin: about $1 \mathrm{~mm}$. In that model the dry deposition velocity is expressed as:

$$
v_{d}=\frac{k_{C} k_{D}+v_{g}^{2}+k_{C} v_{g}+k_{D} v_{g}}{k_{C}+2 v_{g}} .
$$

Where $v_{\mathrm{g}}$ is gravity settlement velocity $(\mathrm{m} / \mathrm{s}), \mathrm{k}_{C}$ is transfer velocity in constant flux layer $(\mathrm{m} / \mathrm{s}), \mathrm{k}_{D}$ is transfer velocity in deposition layer $(\mathrm{m} / \mathrm{s})$.

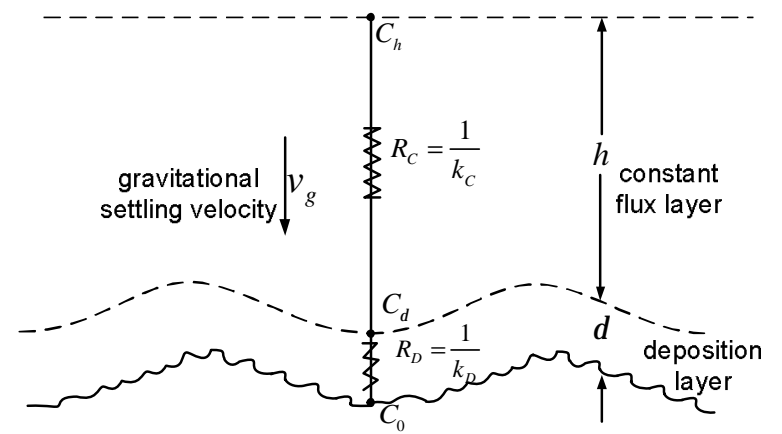

Fig. 1 the model for particles dry deposition to sea surface (adapted from Slinn,1980).

The main mechanism of aerodynamic propagation in the vertical flux of nuclide in the constant flux layer is turbulent mixing. The transfer velocity in constant flux layer can be calculated by the following equations [7]:

$$
\begin{aligned}
& k_{C}=\frac{\kappa u_{*}}{\left[\ln \left(\mathrm{z} / \mathrm{z}_{0}\right)-\Psi_{h}(\mathrm{z} / \mathrm{L})+\Psi_{h}\left(\mathrm{z}_{0} / \mathrm{L}\right)\right]} \\
& u_{*}=\sqrt{C_{d} U_{10}^{2}} \\
& C_{d}=\left(0.75+0.067\left|\mathrm{U}_{10}\right|\right) \times 10^{-3} \\
& \mathrm{z}_{0}=0.0185 u_{*}^{2} / g \\
& \Psi_{h}=\frac{-5 z}{L} \text { for } z / L>0.05 \\
& \Psi_{h}=2 \ln \left(\left(1+\mathrm{x}^{2}\right) / 2\right) ; \mathrm{x}=(1-15 \mathrm{z} / \mathrm{L})^{1 / 4} \text { for } z / L<-0.05 \\
& \Psi_{h}=0 \text { for }|z / L|<0.05 \\
& L=\frac{u_{*}^{3} c_{p} \rho \bar{T}}{\kappa g H} .
\end{aligned}
$$

Where $\mathrm{z}$ is reference height usually $10 \mathrm{~m}, \mathrm{U}_{10}$ is wind velocity at height $10 \mathrm{~m}(\mathrm{~m} / \mathrm{s}), C_{d}$ is drag coefficient, $u_{*}$ is friction velocity $(\mathrm{m} / \mathrm{s}), \mathrm{z}_{0}$ is surface roughness, $\kappa$ is von Karman's constant $=0.4$, $\Psi_{h}$ is stability function.

The gravitational settling velocity is given by Stokes Law as: 


$$
v_{g}=\frac{\rho_{p} g d^{2}}{18 \mu}
$$

Where $\rho_{p}$ is particle density $\left(\mathrm{kg} / \mathrm{m}^{3}\right), \mathrm{d}$ is particle diameter $(\mathrm{m}), \mu$ is air viscosity $(\mathrm{Pa} \cdot \mathrm{s})$.

The transfer velocity in deposition layer can be calculated by the following equations $[8,9]$ :

$$
\begin{aligned}
& k_{D}=\frac{1}{\kappa} C_{\mathrm{d}} U S c^{-1 / 2}+\frac{1}{\kappa} C_{d} U 10^{-\frac{3}{S t}} \\
& S c=\mathrm{v}_{\text {air }} / D_{B} \\
& D_{B} \approx \frac{2.38 \times 10^{-7}}{d}\left(1+\frac{0.163}{d}+0.0548 \exp (-6.66 d) / d\right) \\
& S t=\frac{u_{*}^{2} v_{\mathrm{g}}}{g v_{\text {air }}} .
\end{aligned}
$$

Where $v_{\text {air }}$ is kinematic viscosity $\left(\mathrm{m}^{2} / \mathrm{s}\right) ; D_{B}$ is the diffusivity of particles; $S$ t is Stokes number.

Model validation. Caffery et al. have measured the dry deposition velocity of aerosol particles of different diameters on the RV Lake Guardian ship 19 kilometers east of the Chicago coastline [9]. This paper used the Caffery's experimental data to verify the dry deposition velocity model. The results are shown in Fig. 2. As the picture shown, the simulated values are generally in good agreement with the experimental values. The dry deposition velocity calculation model adopted in this paper is reliable.

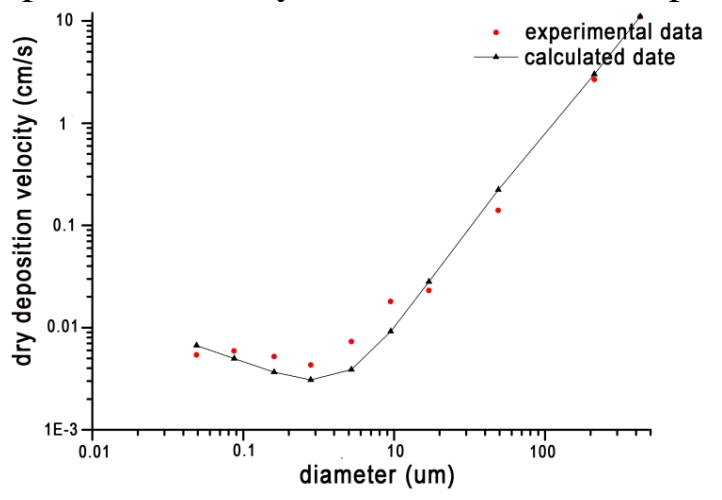

Fig. 2 Comparison of simulated and experimental values

\section{Sensitivity analysis}

Base on the calculation model, in order to further understand dry deposition of nuclide particle, the influence of wind speed, particle diameter and density on dry deposition velocity is analyzed.

Particle diameter. Assuming that the wind speed is $5 \mathrm{~m} / \mathrm{s}$, the atmospheric temperature at sea is $25^{\circ} \mathrm{C}$, and the particle density is $1.879 \times 10^{3} \mathrm{~kg} / \mathrm{m}^{3}$. The dry deposition velocity of particles of different sizes was calculated. The results are shown in Fig. 3. It can be seen from the figure that the dry deposition velocity of the particles is related to the diameter, and the dry settling velocity of the particles with a diameter of $0.3 \mathrm{um}$ is the smallest; when the diameter is smaller than this value, the dry deposition velocity of the particles is inversely proportional to the diameter; when the diameter is larger than this value, The dry deposition velocity of particles is proportional to the diameter. 


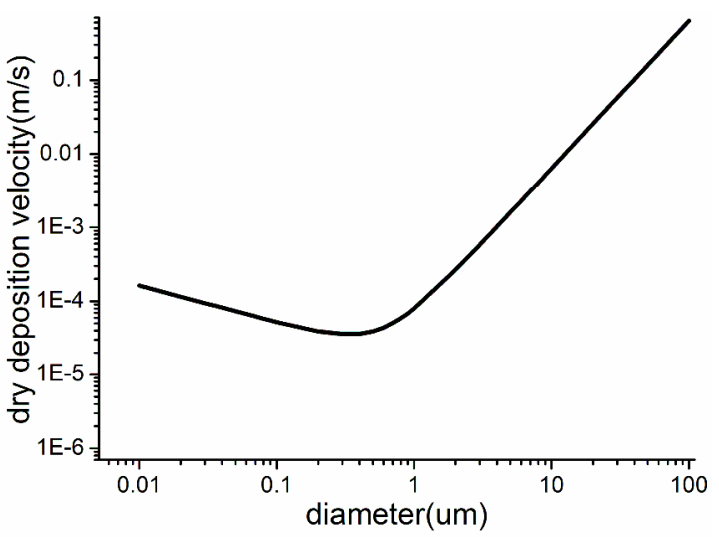

Fig. 3 Particle dry deposition velocity versus particle diameter

Wind speed. Assuming that the atmospheric temperature is $25^{\circ} \mathrm{C}$ and the particle density is $1.879 \times 10^{3} \mathrm{~kg} / \mathrm{m}^{3}$, the dry deposition velocity of particles under different wind speeds $(\mathrm{u}=2,5,10,15$ $\mathrm{m} / \mathrm{s}$ ) is calculated. The results are shown in Fig. 4. For particles small than $0.3 \mu \mathrm{m}$ in diameter, the dry deposition velocity is the most sensitive to the wind speed. The larger the wind velocity is, the higher the dry deposition velocity is. The main reason is that the dry deposition velocity of particles with relatively small diameter is affected by the atmospheric turbulent motion. Larger, the greater the wind speed, the greater the transmission coefficient in the constant flux layer. The particles with large diameter are insensitive to wind speed. For particles big than $20 \mathrm{um}$, when the wind speed increases, the dry deposition velocity is almost constant, because the gravitational deposition plays a leading role in the dry deposition process. In addition, the change in wind speed does not affect the relationship between the dry deposition velocity and the diameter of the particles.

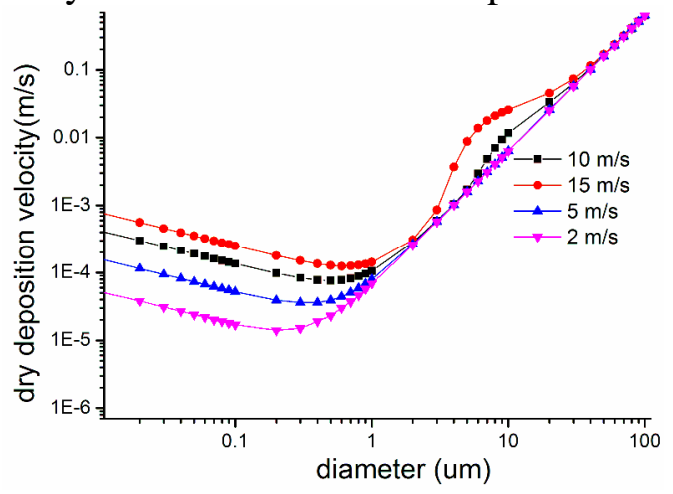

Fig. 4 Effect of wind speed on particles dry deposition

Density. Assuming that the atmospheric temperature is $25^{\circ} \mathrm{C}$ and the wind speed is $2 \mathrm{~m} / \mathrm{s}$, the dry deposition velocity of particles with diameters of $0.1 \mathrm{um}, 1 \mathrm{um}, 10 \mathrm{um}, 20 \mathrm{um}$, and $100 \mathrm{um}$ at different densities are calculated. The results are shown in Fig. 5. As shown in the figure, the dry deposition velocity is insensitive to the particle density for very small diameter particles $(0.1 \mathrm{um}, 1 \mathrm{um})$. For larger diameter particles (10 um, $20 \mathrm{um}, 100 \mathrm{um}$ ), the dry deposition velocity is sensitive to density and is proportional to it. This is because, as can be seen from Eq. 11, Eq. 12, the density of particles mainly affects the gravitational settling velocity. When the diameter is small, the gravitational settling velocity of the particles has little effect on the dry deposition velocity compared with the aerodynamic transfer coefficient in the constant flux layer and the transfer coefficient in deposition layer, so the dry deposition velocity is insensitive to the particle density. When the particle diameter is larger, the gravitational settling velocity has a greater influence, so the dry deposition velocity of particles is proportional to the density. 


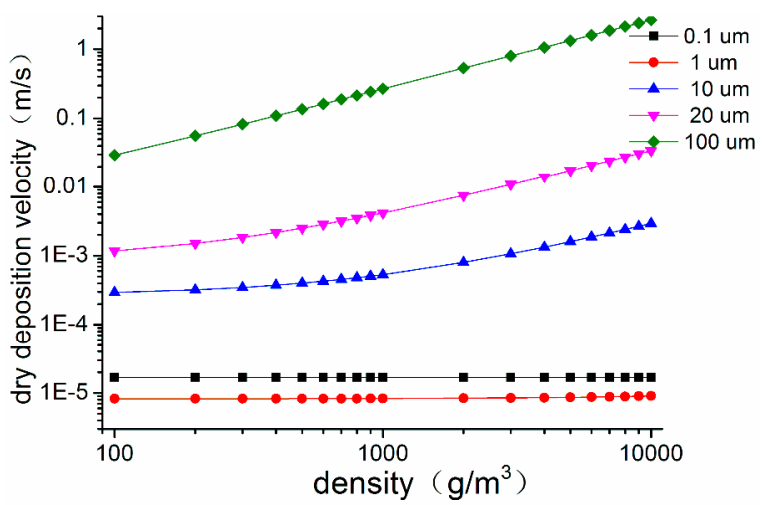

Fig. 5 Effect of density on dry deposition velocity

\section{Conclusions}

In this paper, we established the calculation model of dry deposition velocity of nuclide particle onto sea surface, then, verified the model by experimental data, finally, analyzed the effects of the diameter, wind speed, and particle density on dry deposition velocity. The main conclusions are:

(1) dry deposition velocity of nuclide particle onto sea surface is related to its diameter, for small nuclides, the deposition velocity is inversely proportional to diameter; for large nuclide, that is proportional to the diameter.

(2) The wind speed will affect the dry deposition velocity of the particles, but the sensitivity of dry deposition velocity to the wind speed is related to the diameter. for very small diameter nuclides, the larger wind velocity is, the higher dry deposition velocity is. for larger particles, that is insensitive to wind velocity. In addition, the wind speed does not affect the relationship between dry deposition velocity and diameter.

(3) The density of particle will affect the dry deposition velocity, but the sensitivity of dry deposition velocity to the density is related to the diameter. For small diameter particles, the dry deposition velocity is insensitive to density. For larger diameter particles, the dry deposition velocity is sensitive to density and is proportional to it.

\section{References}

[1] A Bolsunovsky, D Dementyev: Journal of Environmental Radioactivity, Vol. 11 (2011), p.1061-1064.

[2] W T Hwang, E H Kim, K S Suh: Journal of Korea Atomic Radiation Protection, Vol. 5 (2002), p.165-170.

[3] A Vargas, A Camacho: Applied Radiation \& Isotopes Including Data Instrumentation \& Methods for Use in Agriculture Industry \& Medicine, Vol. 1 (2016), p.441-443.

[4] H Wershofen, D C Aumann: Journal of Radioanalytical \& Nuclear Chemistry, Vol. 137 (2014), p.373-379.

[5] S M Mohan: International Journal of Environmental Science \& Technology, Vol. 13 (2016), p.387-402.

[6] S A Slinn, W G N Slinn: Atmospheric Environment, Vol. 9 (1980), p.1013-1016.

[7] S C Pryor, L L Sørensen: Journal of Applied Meteorology, Vol. 5 (2000), p.725-731.

[8] J H Seinfeld, S N Pandis: Environment Science \& Policy for Sustainable Development, Vol. 7 (1998), p.26.

[9] P F Caffrey, J M Ondov, M J Zufall: Environmental Science \& Technology, Vol. 32 (1998), p. 1615-1622. 